\title{
Effect of Theophylline on Metabolic and Ventilatory Response to Hypoxemia during Quiet Sleep in Piglets
}

\author{
HERNAN PORRAS, ${ }^{1}$ BRIAN MEEHAN, AND AURORE CÔTÉ ${ }^{2}$ \\ Division of Respiratory Medicine and The Jeremy Rill Centre for SIDS and Respiratory Control \\ Disorders, Department of Pediatrics, Montreal Children's Hospital-Research Institute, McGill University, \\ Montréal, Canada
} \begin{abstract}
ABST
Theophylline, a drug frequently used in newborns, stimulates
respiration and increases the metabolic rate in a sustained fashion; hypoxemia, on the other hand, decreases metabolic rate and increases ventilation slightly and, at times, only transiently. This study looked at the effect of theophylline on the metabolic and ventilatory response to hypoxemia in piglets. We studied two groups of piglets during normoxia and hypoxemia: first during a baseline period; and second, after the infusion of either theophylline or a placebo. All studies were done in quiet sleep, $2 \mathrm{~d}$ after instrumentation was performed to place vascular catheters and electroencephalographic electrodes. $\mathrm{O}_{2}$ consumption $\left(\mathrm{V}_{\mathrm{O}_{2}}\right)$ and $\mathrm{CO}_{2}$ production $\left(\dot{\mathrm{V}}_{\mathrm{CO}_{2}}\right)$ were measured in a metabolic chamber, and alveolar ventilation $\left(\dot{\mathrm{V}}_{\mathrm{A}}\right.$ ) was then derived from $\dot{\mathrm{V}}_{\mathrm{CO}_{2}}$ and $\mathrm{PaCO}_{2}$. We found that theophylline did not abolish the small decrease in oxygen consumption brought about by hypoxemia. Nor did theophylline augment the ventilatory response to hypoxemia. In fact, the percent change in alveolar ventilation decreased slightly: going from $17 \pm 8 \%$ during the baseline period to $9 \pm$ $6 \%(p<0.005)$ after theophylline administration. We found a
\end{abstract}

significant increase in respiratory exchange ratio $(R)$ in response to hypoxemia (from $0.87 \pm 0.05$ to $0.97 \pm 0.04, p<0.001$ ) However, after the administration of theophylline, additional exposure to hypoxemia did not result in a change in $R$. In summary, our results show that, in sleeping newborn piglets, theophylline does not abolish the decrease in oxygen consumption observed in response to hypoxemia; nor does it enhance the ventilatory response to a moderate degree of hypoxemia. (Pediatr Res 38: 926-931, 1995)
Abbreviations
$\mathrm{Fio}_{2}$, fractional concentration of inspired oxygen $\mathrm{FiCO}_{2}$, fractional concentration of inspired $\mathrm{CO}_{2}$
$\mathrm{PaCO}_{2}$, partial pressure of arterial $\mathrm{CO}_{2}$
$\mathrm{PACO}_{2}$, partial pressure of alveolar $\mathrm{CO}_{2}$
$\dot{\mathrm{V}}_{2}$, oxygen consumption
$\dot{\mathrm{V}}_{\mathrm{CO}_{2}}, \mathrm{CO}_{2}$ production
$\dot{\mathrm{V}}_{\mathrm{A}}$, alveolar ventilation
EEG, electroencephalograph

Compared with adults, newborns have high demands for oxygen. They also, however, are prone to diseases in which hypoxemia occurs. These include pulmonary involvement secondary mostly to prematurity but also infections and apnea of infancy. These conditions are often treated with theophylline, a respiratory stimulant $(1,2)$.

The effect of theophylline on the response to hypoxemia in newborns has been studied largely from the point of view of ventilation. The studies, however, have shown conflicting results: both a stimulation of the ventilatory response to hypoxemia $(3,4)$ and no effect at all $(5)$. In fact, in one study of

\footnotetext{
Received September 21, 1994; accepted June 20, 1995.

Correspondence and reprints requests: Aurore Côté, Division of Respiratory Medicine (D-380), Montreal Children's Hospital, 2300 rue Tupper, Montréal, Canada H3H 1P3.

Supported by the Association Pulmonaire du Québec and, in part, by the Medical Research Council of Canada (Grant MA-10258) and the Heart and Stroke Foundation of Canada.

'Visiting physician from the University of Cali, Colombia.

${ }^{2}$ Research Scholar of the Fonds de la recherche en santé du Québec.
}

newborn piglets in which $\mathrm{PaCO}_{2}$ was measured along with minute ventilation (4), the use of theophylline, although stimulating the ventilatory response to hypoxemia, did not yield the expected diminution of $\mathrm{PaCO}_{2}$. Therefore, even though metabolic rate was not measured, the results suggest that the metabolic rate $\left(\mathrm{CO}_{2}\right.$ production) had increased, thereby increasing ventilation after theophylline administration.

Clearly, it is important to know the metabolic rate when the effect of theophylline during hypoxemia is being assessed in newborns, for at that age theophylline and hypoxemia have different effects on ventilation and metabolic rate. Indeed, although hypoxemia increases ventilation slightly in newborns-sometimes only transiently-(reviewed in Refs. 6 and $7)$ and also depresses metabolic rate $(8,9)$, theophylline increases both ventilation and metabolic rate in a sustained fashion $(10,11)$. The decrease in metabolic rate in response to hypoxemia is viewed as an adaptation of the newborn to low oxygen content $(9,12,13)$. Nonetheless, if theophylline abol- 
ishes the decrease in metabolic rate that occurs in response to hypoxemia, the consequences could be deleterious for those hypoxemic newborns so often given theophylline. So far, no study has explored the interaction of theophylline and hypoxemia with metabolic rate and ventilation in newborns.

The purpose of the present study was to determine whether, in newborn piglets, theophylline modifies the metabolic response to hypoxemia. We elected to measure metabolic and ventilatory parameters during quiet sleep to avoid any stimulation of respiration caused by the general stimulation of activity, secondary to theophylline, during the awake state. We have shown in the past that, after administration of theophylline, quiet sleep is present in sufficient amounts to make such study feasible, but that active sleep is greatly diminished (10).

\section{METHODS}

Animal preparation. A total of 16 piglets were studied at a mean age of $7 \pm 1 \mathrm{~d}$ (mean $\pm \mathrm{SD}$ ) and a mean weight of 2.7 $\pm 0.5 \mathrm{~kg}$. The animals were obtained a few days before the experiments and kept in our animal quarters. We provided them with sow milk replacer (Wetnurse; JEFFO Co. StHyacinthe, Québec, Canada) ad libitum throughout the day and night and monitored their weight gains closely. Only those animals that had a normal weight gain $(\approx 100 \mathrm{~g} /$ day $)$ were used for the experiments. The environmental temperature in the animal quarters was kept between 26 and $30^{\circ} \mathrm{C}$; the sleeping area was provided with sufficient additional heat to maintain a thermoneutral environment $\left(32-33^{\circ} \mathrm{C}\right)(14)$.

We performed surgery for catheter insertion 2-3 d before the experiments, using halothane $/ \mathrm{N}_{2} \mathrm{O} / \mathrm{O}_{2}$ anesthesia. One catheter was placed in the axillary vein for theophylline or placebo infusion; a second cathether was placed in the descending aorta from a femoral artery for blood gas sampling and monitoring of blood pressure and heart rate (polyvinyl, TYGON microbore tubing; Norton Co., Wayne, NJ). We also instrumented the animals with s.c. electrodes (platinum subdermal type E2; Grass Instruments, Quincy, MA) for EEG recording. Once the anesthesia was stopped, the animals woke rather rapidly (within $15-20 \mathrm{~min}$ ); a few hours after surgery, they seemed to behave, walk, and feed normally.

Measurement of total body $\mathrm{O}_{2}$ consumption and $\mathrm{CO}_{2}$ production, and alveolar ventilation. We used the closed-system method for the measurement of these parameters. The animals were studied in a totally sealed plexiglass chamber $(44.6 \times 45$ $\times 60 \mathrm{~cm}$; volume, $120.4 \mathrm{~L}$ ). We kept the chamber's temperature in the thermoneutral range for piglets; that is, between 32 and $33^{\circ} \mathrm{C}$ with the ambient temperature adjusted to $\pm 0.1^{\circ} \mathrm{C}$ (Telethermometer; Yellow Spring Instruments, Yellow Springs, OH). We used a gas circulation system, so the $\mathrm{CO}_{2}$ and $\mathrm{O}_{2}$ levels in the chamber could be adjusted between the periods of metabolic rate measurement. By circulating the ambient air of the chamber through a container of $\mathrm{CaSO}_{4}$ (Drierite), we maintained the $\mathrm{H}_{2} \mathrm{O}$ vapor at approximately 20 $\pm 5 \%$ of relative humidity. During the recording periods, care was taken to maintain a constant level of ambient temperature and humidity in the chamber, thereby restricting the variables that might cause $\mathrm{FiO}_{2}$ changes.
We measured total body $\mathrm{O}_{2}$ consumption and $\mathrm{CO}_{2}$ production by continuously recording the drop in $\mathrm{FiO}_{2}$ and the increase in $\mathrm{FiCO}_{2}$ in the animals' metabolic chamber. An electrochemical cell oxygen analyzer (model S-3A/1) and sensor (model N-22 M; AMETEK, Applied Electrochemistry, Pittsburgh, PA) was used to measure the $\mathrm{FiO}_{2}$ (dry). An infrared $\mathrm{CO}_{2}$ analyzer (model CD-3A) and sensor (model P-61B; AMETEK, Applied Electrochemistry) was used to measure the $\mathrm{FiCO}_{2}$. This equipment is sensitive to a $\pm 0.01 \%$ change in $\mathrm{FiO}_{2}$ or $\mathrm{FiCO}_{2}$ and has an accuracy of $\pm 0.02 \%$ and a $90 \%$ response time of $100 \mathrm{~ms}$. We calibrated these instruments with three different gas mixtures of $\mathrm{O}_{2}$ and $\mathrm{CO}_{2}$, the range of which corresponded to the range of values used during the studies. To ensure that all measurements of $\dot{\mathrm{V}}_{2}$ and $\dot{\mathrm{V}}_{\mathrm{CO}_{2}}$ were accurate, we regularly tested our system's ability to measure a small, precisely known change in $\mathrm{O}_{2}$ and $\mathrm{CO}_{2}$ levels, both in room air and with a hypoxic mixture similar to that used for the study. For that purpose, we added $\mathrm{O}_{2}$ (or $\mathrm{CO}_{2}$ ) to the chamber, through a precisely calibrated flowmeter, at a rate of 20 and 30 $\mathrm{mL} / \mathrm{min}$ for a known period of time (usually between 5 and 10 $\mathrm{min}$ ). This flow rate represents a value for oxygen consumption (or $\mathrm{CO}_{2}$ production) of $10-15 \mathrm{~mL} / \mathrm{kg} / \mathrm{min}$ in our piglets. We were able to measure the expected changes exactly within $\pm 0.01 \%$ of $\mathrm{FiO}_{2}$ or $\mathrm{FiCO}_{2}$. In the past, we obtained very reproducible $\dot{\mathrm{V}}_{2}$ and $\dot{\mathrm{V}}_{\mathrm{CO}_{2}}$ results using that method (10).

Measurements were made over a period of approximately 15 min (sufficient time to measure $\mathrm{O}_{2}$ consumption and $\mathrm{CO}_{2}$ production), during which time neither $\mathrm{FiO}_{2}$ nor $\mathrm{FiCO}_{2}$ changed by more than 0.3 (gas circulation system closed). The measurements were made when the piglets were in quiet sleep, starting at least $30 \mathrm{~s}$ after that state had been clearly identified by EEG and behavioral criteria. The time delay of $30 \mathrm{~s}$ was chosen because, with our system, it represents three times the delay to see a change in the $\mathrm{FiO}_{2}$ or $\mathrm{FiCO}_{2}$. We calculated $\mathrm{O}_{2}$ consumption as follows:

$$
\begin{aligned}
& \dot{\mathrm{VO}}_{2}\left(\mathrm{mLO}_{2} \cdot \mathrm{min}^{-1} \cdot \mathrm{kg}^{-1}\right) \\
& =\frac{\Delta \mathrm{FiO}_{2}(\% / \mathrm{min}) \times[\mathrm{vol} \text { of chamber }(\mathrm{mL})-\mathrm{vol} \text { of animal }]}{\text { weight of animal }(\mathrm{kg})}
\end{aligned}
$$

We calculated $\mathrm{CO}_{2}$ production $\left(\dot{\mathrm{V}}_{2}\right)$ in much the same way, replacing $\Delta \mathrm{FiO}_{2}$ in the equation by $\Delta \mathrm{FiCO}_{2}$. We derived alveolarventilation from the value of $\mathrm{CO}_{2}$ production and $\mathrm{PaCO}_{2}$ as follows:

$$
\text { Alveolar ventilation }=\frac{\mathrm{CO}_{2} \text { production }}{\mathrm{PACO}_{2}} \times K
$$

where $K$ is a constant used as a correcting factor to convert $\dot{\mathrm{V}}_{\mathrm{CO}_{2}}$ (and $\dot{\mathrm{V}}_{2}$ ) to standard temperature and pressure dry. We used $\mathrm{PaCO}_{2}$ to estimate $\mathrm{PACO}_{2}$. Blood gases and $\mathrm{pH}$ were analyzed with an ABL30 blood gas analyzer (Radiometer Copenhagen, Copenhagen, Denmark), and values were corrected for the body temperature of the animals.

Body temperature. Throughout the studies, we recorded rectal temperature in each animal. For that purpose, a flexible rectal probe (electronic thermometer; Physitemp, Clifton, NJ) 
was inserted 3-4 cm deep. It was fixed carefully to the tail, before being extended with catheters and electrodes outside the chamber. The animals adapted to the probe immediately and appeared unaffected by it throughout the study.

Hypoxemia induction. We induced hypoxemia by adding a mixture of nitrogen and oxygen to the chamber, thereby progressively decreasing the $\mathrm{FiO}_{2}$ so as to obtain a $\mathrm{PaO}_{2}$ between 45 and $50 \mathrm{~mm} \mathrm{Hg}\left(11-12 \% \mathrm{FiO}_{2}\right)$. This induction was done over a period of $15 \mathrm{~min}$. In preliminary experiments, we had noted that a more rapid induction of hypoxemia (less than 5 min) usually agitated the animals, preventing appropriate sleep for several minutes thereafter. We established the level of $\mathrm{PaO}_{2}$ at no lower than $45 \mathrm{~mm} \mathrm{Hg}$, inasmuch as the piglets' length of time asleep diminished significantly below that level and agitation emerged in the theophylline group.

Determination of behavioral states. We used both EEG and behavioral criteria to determine each piglet's state of consciousness $(10,15)$. We studied quiet sleep only. Quiet sleep was determined according to the following criteria: eyes closed, no movement, regular respiratory and heart rates, and high amplitude slow waves on the EEG.

Experimental protocol. We separated the animals into two groups: placebo $(n=6)$ and theophylline $(n=10)$. The placebo group was used to establish whether a repeat exposure to hypoxemia in the same piglets would result in similar metabolic and cardiorespiratory responses. During all experiments, the animals were permitted to move freely and to stay awake or fall asleep spontaneously.

The baseline study started at about $1000 \mathrm{~h}$, usually lasting about $3 \mathrm{~h}$. After an initial 45-min recording, during which three measurements of metabolic and cardiorespiratory parameters were made, we began the induction of hypoxemia. After a stabilization period of approximately $15 \mathrm{~min}$, we started the recordings again, repeating the measurement of metabolic and cardiorespiratory parameters. The total duration of the hypoxic exposure (including the induction time) lasted $90 \mathrm{~min}$. The animals were then returned to their quarters and allowed to eat and recuperate for at least $2.5 \mathrm{~h}$.

The second part of the study started with another $45 \mathrm{~min}$ of baseline measurements. We then administered the theophylline preparation, or the equivalent amount of normal saline as a placebo, infusing continuously over $30 \mathrm{~min}$. We did three measurements in the following $45 \mathrm{~min}$ and then induced hypoxemia again and repeated the measurements.

During all studies, we recorded respiratory rate with respiratory inductive plethysmography (RESPITRACE) and blood pressure with a pressure transducer (model P23ID; Gould, Oxnard, CA). All data were recorded on paper (Grass model 7E Polygraph; Grass Instrument, Quincy, MA) for further analysis. Heart rate was recorded continuously by a cardiotachometer (model 7P4H, Grass Instruments) triggered from the arterial pressure pulse. This protocol was approved by the Animal Care Committee at our institution.

Determination of blood levels of theophylline. We determined theophylline blood levels by the Tdx Theophylline II assay (an immunoassay). Blood samples were obtained twice: immediately after the drug infusion and at the end of the study. In the past, we determined that a $9 \mathrm{mg} / \mathrm{kg}$ dose of aminophyl- line, diluted to a volume of $15 \mathrm{~mL}$ with a normal saline solution $(0.9 \%)$ and given over $30 \mathrm{~min}$, would give us a stable blood level of approximately $40 \mu \mathrm{M} / \mathrm{L}(7.3 \mathrm{mg} / \mathrm{L})$ for the next $3 \mathrm{~h}(10)$. We did not aim at higher blood levels of theophylline because we had previously noted that, at higher levels, our piglets scarcely slept.

Data and statistical analysis. We considered as valid, each quiet sleep episode that lasted longer than five minutes (excluding the first $30 \mathrm{~s}$ ). For calculation of $\dot{\mathrm{V}}_{2}$ and $\dot{\mathrm{V}}_{\mathrm{CO}_{2}}$, a mean value was obtained for each episode of quiet sleep (range of two to four episodes) achieved during the baseline period and after the drug administration (postinfusion period), during both normoxia and hypoxemia. For heart rate, respiratory rate, and blood pressure, we systematically analyzed the 2 nd and 3 rd min of each episode of quiet sleep.

Before analyzing the effect of theophylline on the response to hypoxemia, we did two statistical tests. First, we examined whether the animals had returned to baseline values at the end of their 2-3-h rest period, that is, before the start of the infusion of drug or placebo (paired $t$ test). No difference was found. Second, to evaluate whether time affects the various parameters during hypoxemia, we performed a single factor analysis of variance on the results of each hypoxemia exposure. Because no significant effect of time was found, we then averaged all the values obtained during hypoxemia for each variable-in each group and for each exposure. At that point, we felt justified in comparing the different experimental conditions.

Next, we performed a two-way analysis of variance across conditions to determine whether the second exposure to hypoxemia in the placebo group differed from the first. We performed the same type of analysis for the theophylline group, and we used the Newman-Keuls test to evaluate differences between specific means. To evaluate whether theophylline had an effect on the ventilatory response to hypoxemia, we did a paired $t$ test analysis on the percent difference between normoxia and hypoxemia from the two exposures (baseline and postinfusion) for each variable. Differences between mean values were considered significant when $p<0.05$.

\section{RESULTS}

Placebo group. For the six piglets that received the placebo, no significant difference emerged from a comparison of the responses to the first and second exposure to hypoxemia (Fig. 1). As well, the placebo group's response to hypoxemia did not differ from that of the theophylline group's baseline period. We therefore felt justified in comparing the theophylline group's response to hypoxemia during the baseline period with that recorded after the administration of theophylline.

Theophylline group. The mean serum levels of theophylline were as follows: $42 \pm 4 \mu \mathrm{M} / \mathrm{L}(7.6 \mu \mathrm{g} / \mathrm{mL})$ after the end of the infusion; and $38 \pm 5 \mu \mathrm{M} / \mathrm{L}(6.9 \mu \mathrm{g} / \mathrm{mL})$ at the end of the study, approximately $2.5 \mathrm{~h}$ later.

Effect of theophylline. Both $\mathrm{V}_{\mathrm{A}}$ and $\dot{\mathrm{V}}_{2}$ increased significantly after the administration of theophylline, whereas $\mathrm{PaCO}_{2}$ decreased significantly. The other variables did not change significantly, and there was no change in body temperature. 

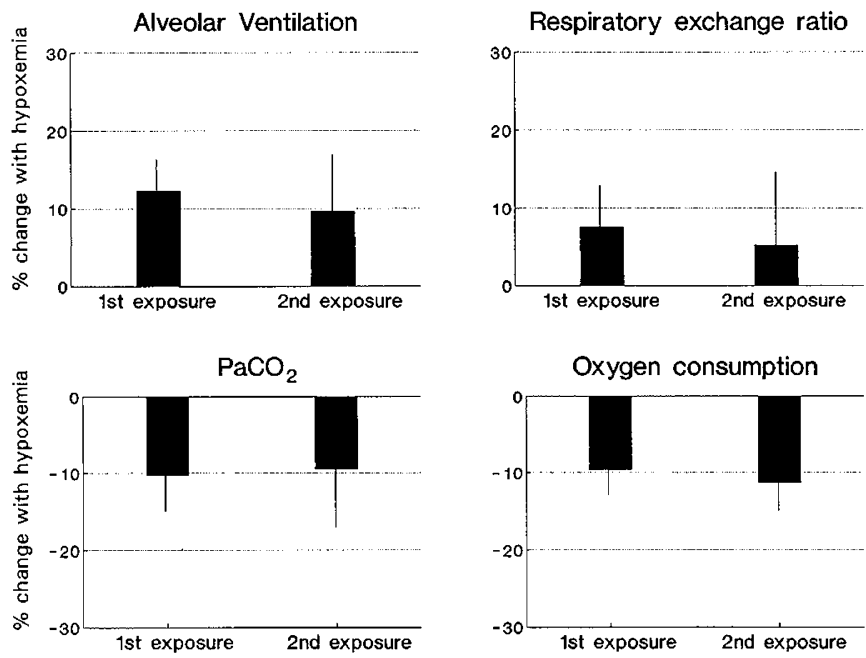

Figure 1. Comparison of the percent change with hypoxemia for the two exposures in the placebo group (results expressed as mean $\pm \mathrm{SD}$ ). Note that there was no significant difference for any of the variables.

Effect of hypoxemia. Hypoxemia, in the theophylline group, increased the $\dot{V}_{\mathrm{A}}$, respiratory exchange ratio $(R)$, respiratory rate, and heart rate (see Table 1 for cardiorespiratory and metabolic variables), whereas both $\mathrm{PaCO}_{2}$ and $\mathrm{V}_{2}$ decreased. Neither $\dot{\mathrm{V}}_{2}$ nor the systolic and diastolic blood pressures were affected. There was also no effect of hypoxemia on body temperature.

For $\dot{V}_{\mathrm{A}}$ and $R$, however, the response to hypoxemia differed before and after the administration of theophylline (Fig. 2). In all 10 animals studied, the percent change in $V_{A}$ with hypoxemia was lower after the administration of theophylline than during the baseline period $(8.9 \pm 6.1 \%$ versus $17.0 \pm 8.1 \%, p$ $<0.005$ ). Also, whereas $R$ increased significantly with hypoxemia in the baseline part of the study, no significant change in $R$ occurred with hypoxemia after the administration of theophylline. The changes in $\dot{\mathrm{V}}_{2}$ and $\dot{\mathrm{V}}_{\mathrm{CO}_{2}}$ during hypoxemia were not significantly different before and after the administration of theophylline. The percent drop in $\mathrm{V}_{2}$ with hypoxemia was 9.6 $\pm 4.0 \%$ and $11.3 \pm 3.7 \%$, respectively, during baseline and after theophylline administration. Finally, there were no significant changes in the heart and respiratory rates, blood pressure, and body temperature throughout the study.

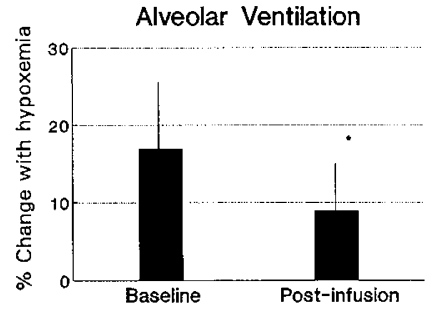

Respiratory exchange ratio

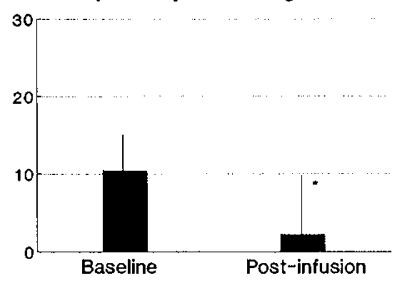

Figure 2. Percent change with hypoxemia of both alveolar ventilation and respiratory exchange ratio (results expressed as mean $\pm \mathrm{SD}$ ). Note that in the baseline period, for both alveolar ventilation and respiratory exchange ratio, the percent change with hypoxemia was significantly higher than that after theophylline administration. ${ }^{*} p<0.005$, paired $t$ test between baseline and postinfusion.

\section{DISCUSSION}

The major finding of this study is that, in our sleeping piglets, the use of theophylline modified neither the metabolic nor ventilatory response to hypoxemia. These results differ somewhat from those of other investigators. We will therefore consider the methodologic differences between the studies before discussing possible explanations of our results.

Methodologic differences. First, unlike other studies of newborn animals exposed to theophylline and hypoxemia, we used nonanesthetized animals. Because most anesthetic agents have been shown to depress both ventilation and the ventilatory response to hypoxemia (reviewed in Ref. 16), we thought that, in the anesthetized animal studies, theophylline might have reversed the depression of ventilation brought about by anesthesia, thereby modifying the ventilatory response to hypoxemia. Second, our piglets had intact upper airways and we did not use any respiratory apparatus. Note that, although such apparatuses might not modify the magnitude of the ventilatory response, they likely modify the pattern of breathing and perhaps the dead space ventilation as well. Finally, we exposed our animals to a moderate degree of hypoxemia for approximately $2 \mathrm{~h}$. In addition, we induced alveolar hypoxia over a period of $15 \mathrm{~min}$ and studied the animals after a stabilization period of at least $15 \mathrm{~min}$. Thus our results do not show the classical biphasic ventilatory pattern obtained by other investigators in the first $10 \mathrm{~min}$ of hypoxemia in piglets $(4,5)$ and in newborns of several mammal species (17-20). We used such a progressive induction of hypoxemia because, once we had seen

Table 1. Metabolic and cardiorespiratory response to hypoxemia in the theophylline group

\begin{tabular}{|c|c|c|c|c|}
\hline \multirow[b]{2}{*}{ Response } & \multicolumn{2}{|c|}{ Baseline } & \multicolumn{2}{|c|}{ Postinfusion } \\
\hline & Normoxia & Hypoxemia & Normoxia & Hypoxemia \\
\hline$\dot{\mathrm{V}}_{2}\left(\mathrm{~mL} \cdot \mathrm{min}^{-1} \cdot \mathrm{kg}\right)$ & $10.7 \pm 1.7$ & $9.7 \pm 1.4 * *$ & $11.8 \pm 1.8$ & $10.5 \pm 1.8^{* *}$ \\
\hline$\dot{\mathrm{V}}_{2}\left(\mathrm{~mL} \cdot \mathrm{min}^{-1} \cdot \mathrm{kg}\right)$ & $9.3 \pm 1.9$ & $9.4 \pm 1.7$ & $10.3 \pm 2.1$ & $9.5 \pm 2.2$ \\
\hline $\mathrm{PaCO}_{2}(\mathrm{kPa})$ & $5.0 \pm 0.5$ & $4.3 \pm 0.5^{* *}$ & $4.6 \pm 0.5$ & $4.0 \pm 0.4^{*}$ \\
\hline$\dot{\mathrm{V}}_{\mathrm{A}}\left(\mathrm{mL} \cdot \min ^{-1} \cdot \mathrm{kg}\right)$ & $219 \pm 40$ & $256 \pm 53 * *$ & $262 \pm 60$ & $285 \pm 70^{*}$ \\
\hline$R\left(\dot{\mathrm{V}}_{\mathrm{CO}_{2}} / \mathrm{V}_{2}\right)$ & $0.87 \pm 0.05$ & $0.97 \pm 0.04 * *$ & $0.87 \pm 0.04$ & $0.89 \pm 0.07$ \\
\hline Respiratory rate (breaths/min) & $30 \pm 6$ & $37 \pm 11 * *$ & $30 \pm 7$ & $34 \pm 9 *$ \\
\hline Heart rate (beats/min) & $146 \pm 32$ & $190 \pm 39 * *$ & $144 \pm 32$ & $189 \pm 45^{* *}$ \\
\hline \multicolumn{5}{|l|}{ Blood pressure $(\mathrm{mmHg})$} \\
\hline Systolic & $99 \pm 14$ & $99 \pm 15$ & $97 \pm 11$ & $101 \pm 12$ \\
\hline Diastolic & $65 \pm 12$ & $69 \pm 12$ & $63 \pm 12$ & $67 \pm 13$ \\
\hline
\end{tabular}

\footnotetext{
$* p<0.01$.
}

** $p<0.005$ (hypoxemia vs normoxia). 
from our preliminary studies that a quick exposure to alveolar hypoxia invariably awakens the animals who then become agitated, we realized that our planned study in quiet sleep would be impossible, especially after theophylline administration.

Metabolic rate response. The metabolic rate response to hypoxemia was not significantly modified after the administration of theophylline to our piglets. Indeed, the small decrease in oxygen consumption with hypoxemia during the baseline period was still present after theophylline administration, despite the slight overall increase in metabolic rate. A decrease in oxygen consumption upon exposure to hypoxemia has been described in various newborn mammals $(8,12,21$, 22) and in piglets studied in similar conditions and at an age similar to ours (9). It has been shown that this decrease in oxygen consumption is not accompanied by either lactate accumulation (21) or accumulation of an $\mathrm{O}_{2}$ deficit $(13,22)$, both signs of tissue hypoxia. This led to the suggestion that, during periods of $\mathrm{O}_{2}$ limitation, newborns actually decrease some of their oxygen consumption-but without signs of $\mathrm{O}_{2}$ deficit-by decreasing nonessential metabolism (processes requiring $\mathrm{O}_{2}$ that are part of normal metabolism but not essential for survival) $(13,22)$. If this phenomenon does represent an adaptation of the newborn to low levels of oxygen, the strategy may well be preserved at the theophylline blood level achieved in our study - a level also used in treatment of human newborns.

It could be argued, however, that the decrease in metabolic rate observed in our piglets was really rather slight. Several species (mice, rats, and kittens, for instance) have a 30--50\% decrease in oxygen consumption with hypoxemia (8). The major characteristics of these species are their small size and poor overall development at birth. We believe, however, that our piglet model of hypoxemia is closer to what occurs in human newborns, who decrease their oxygen consumption by only $10-15 \%$ (23) upon exposure to mild hypoxemia.

We found that hypoxemia exposure alone was associated with an increased $R$, suggesting an increased utilization of carbohydrates as a source of energy. Although an increased $R$ is only indirect evidence of increased carbohydrate use, it was a consistent and stable finding throughout the $2 \mathrm{~h}$ of hypoxic exposure. The increased $R$ was present in all animals-in the baseline study of the theophylline group as well as the placebo group, even with a repeat exposure to hypoxemia. In adults, an increased $R(24)$ and a greater dependence on carbohydrates to derive energy (25) has already been reported upon exposure to high altitude hypoxemia. In newborns as well, an increase in $R$ with hypoxemia has been reported in several instances $(12,21$, 23). It seems that using carbohydrates as fuel might be advantageous in hypoxemic situations because slightly more energy (per liter of oxygen used) is liberated by the burning of carbohydrates as opposed to fat (26).

Interestingly, after pretreatment with theophylline, we found no increase in $R$ with hypoxemia. This finding might be explained by the opposing effects of hypoxemia (which increases $R$ ) and theophylline (which decreases $R$ ). The other well known methylxanthine, caffeine, has already been shown to promote fat utilization, thereby decreasing $R$ (toward 0.7 ) in adult humans (27-29). Although it is not known whether this is the case for young piglets, our results do suggest such a phenomenon. Nonetheless, before any conclusive statement can be made about substrate utilization during hypoxemia with and without theophylline, direct measurements of substrates would be required.

Ventilatory response to hypoxemia. It was expected that, by stimulating both ventilation and metabolic rate, theophylline would increase the ventilatory response to hypoxemia. However, although an increase in ventilation and oxygen consumption after theophylline administration did occur in normoxia, we saw no increase in the ventilatory response to hypoxemia. Below we discuss several explanations for that phenomenon.

First, it is possible that the ventilatory drive in response to hypoxemia was increased by theophylline but counterbalanced in the end by hypocapnia's depressive effect on respiration. In our piglets, the level of $\mathrm{PaCO}_{2}$ after theophylline administration was significantly lower than that of the baseline period. The presence of hypocapnia can then explain the smaller increase in the ventilatory response to hypoxemia after theophylline administration. We elected not to correct the hypocapnia, for our preliminary experiments had shown that sleep was almost impossible during isocapnic hypoxemia. In the only study of newborn animals in which $\mathrm{PaCO}_{2}$ levels were measured and no attempts made to correct hypocapnia (4), no conclusion concerning the effect of theophylline on the hypoxic ventilatory drive can be drawn, because the large increase obtained in the ventilatory response to hypoxemia after theophylline administration was not accompanied by a proportional decrease in $\mathrm{PaCO}_{2}$; this strongly suggests an increase in metabolically produced $\mathrm{CO}_{2}$ as the cause of the ventilatory increase.

Second, perhaps it is the degree of hypoxemia, and hence the degree of hypoxic ventilatory depression, that acts as one of the major determinants of the effects of theophylline. The level of ventilation achieved during hypoxemia is thought to depend on the interaction between various factors (30), including the stimulatory effect of peripheral chemoreceptors; the depressant effect of hypoxemia, if severe, at the CNS level; and the change in metabolic rate, if any. Depending on the level of hypoxemia, respiratory depression could then become the predominant factor in the ventilatory response, an effect possibly reversible by theophylline. This could explain why Darnall (4) showed an increase in the ventilatory response to hypoxemia after theophylline administration, for his piglets were exposed to severe hypoxemia. In contrast, Long and Lawson's (5) study, with $18 \% \mathrm{FiO}_{2}$, which certainly represents a mild degree of hypoxemia, showed no increase in the ventilatory response to hypoxemia with theophylline.

Finally, one might argue that we used a dose of theophylline that was too low for the determination of any increase in the ventilatory response to hypoxemia, despite increased ventilation and metabolic rates. However, we did not attempt to evaluate the effect of higher doses because sleep would have been difficult to obtain at higher blood levels of theophylline (10). Nevertheless, Long and Lawson (5) did use high doses of theophylline in the newborn piglets but without an increased ventilatory response to hypoxemia. 
It appears, therefore, that theophylline may be able to stimulate the ventilatory response to hypoxemia only in the presence of a preexisting depression of respiration secondary to severe hypoxemia or anesthesia, and in the absence of hypocapnia. We have insufficient data to draw conclusions concerning a dose-dependent effect of theophylline.

In summary, our results show that, during quiet sleep in newborn piglets, theophylline does not abolish the small decrease in $\mathrm{O}_{2}$ consumption brought about by hypoxemia; nor does it enhance the ventilatory response to a moderate degree of hypoxemia.

Acknowledgments. The authors are grateful to Drs. Immanuela Moss and Robert T. Brouillette for their helpful criticism of this manuscript and to Richard Nadler for his skillful technical assistance.

\section{REFERENCES}

1. Marchal F, Bairam A, Vert P 1987 Neonatal apnea and apneic syndrome. In: Stern L (ed) Clinics in Perinatology. The Respiratory System in the Newborn. WB Saunders, Philadelphia, pp 509-529

2. Blanchard PW, Aranda JV 1992 Pharmacotherapy of respiratory control disorders. In: Beckerman RC, Brouillette RT, Hunt CE (eds) Respiratory Control Disorders in Infants and Children. Williams \& Wilkins, Baltimore, pp 352-370

3. Bruce RD, Darnall RA, Althaus JS 1986 Aminophylline reduces hypoxic ventilatory depression without increasing catecholamines. Pediatr Pulmonol 2:218-224

4. Darnall RA 1985 Aminophylline reduces hypoxic ventilatory depression: possible role of adenosine. Pediatr Res 19:706-710

5. Long WA, Lawson EE 1984 Neurotransmitters and biphasic respiratory response to hypoxia. J Appl Physiol 57:213-222

6. Haddad GG, Mellins RB 1984 Hypoxia and respiratory control in early life. Annt Rev Physiol 46:629-643

7. Rigatto H 1992 Maturation of breathing control in the fetus and newborn infant. In: Beckerman RC, Brouillette RT, Hunt CE (eds) Respiratory Control Disorders in Infants and Children. Williams \& Wilkins, Baltimore, pp 61-75

8. Mortola JP. Rezzonico R, Lanthier C 1989 Ventilation and oxygen consumption during acute hypoxia in newborn mammals: a comparative analysis. Respir Physiol 78:31-43

9. Rosen CL, Schecter WS, Mellins RB, Haddad GG 1993 Effect of acute hypoxia on metabolism and ventilation in awake piglets. Respir Physiol 91:307-319

10. Côté A, Blanchard PW, Meehan B 1992 Cardiorespiratory and metabolic effects of doxapram and theophylline in sleeping newborn piglets. J Appl Physiol 72:410-415

11. Rall TW 1990 Drugs used in the treatment of asthma. The methylxanthines, cromolyn sodium and other agents. In: Goodman A, Gilman P, Rall TW, Nies AS, Taylor P (eds) The Pharmacological Basis of Therapeutics. Pergamon Press, New York, pp 618-637

12. Mortola JP, Rezzonico R 1988 Metabolic and ventilatory rates in newborn kittens during acute hypoxia. Respir Physiol 73:55-68

13. Frappell P, Saiki C, Mortola JP 1991 Metabolism during normoxia, hypoxia and recovery in the newborn kitten. Respir Physiol 86:115-124

14. Stanton HC, Mueller RL 1977 Performance of swine chilled during artificial rearing. Am J Vet Res 38:1003-1006

15. Côté A, Haddad GG 1990 Effect of sleep on regional blood flow distribution in piglets. Pediatr Res 28:218-222

16. Pavlin EG, Hornbein TF 1986 Anesthesia and the control of ventilation. In: Fishman AP (ed) Handbook of Physiology. The Respiratory System, Sect. 3, Vol. II. American Physiologic Society, Bethesda, MD, pp 793-813

17. Bureau MA, Zinman R, Foulon P, Begin R 1984 Diphasic ventilatory response to hypoxia in newborn lambs. J Appl Physiol 56:84-90

18. Grunstein MM, Hazinski TA, Schlueter MA 1981 Respiratory control during hypoxia in newborn rabbits: implied action of endorphins. J Appl Physiol 51:122-130

19. Laframboise WA, Guthrie RD, Standaert TA, Woodrum DE 1983 Pulmonary mechanics during the ventilatory response to hypoxemia in the newborn monkey. $\mathrm{J}$ App Physiol 55:1008-1014

20. Rigatto H, Brady JP, da la Torre Verduzco R 1975 Chemoreceptor reflexes in the preterm infants. I. The effect of gestational age on the ventilatory response to inhalation of $100 \%$ oxygen and $15 \%$ oxygen. Pediatrics 55:604-613

21. Moss M, Moreau G, Lister G 1987 Oxygen transport and metabolism in the conscious lamb: the effects of hypoxemia. Pediatr Res 22:177-183

22. Sidi D, Kuipers JRG, Heymann MA, Rudolf AM 1983 Developmental changes in oxygenation and circulatory response to hypoxemia in lambs. Am J Physiol 245:H674-H682

23. Cross KW, Tizard JPM, Trythall DAH 1958 The gaseous metabolism of the newborn infant breathing $15 \%$ oxygen. Acta Paediatr Scand 47:271-273

24. Picon-Reategui E 1966 Insulin, epinephrine and glucagon in the metabolism of carbohydrates at high altitude. Fed Proc 25:1233-1238

25. Brooks GA, Butterfield GE, Wolfe RR, Groves BM, Mazzeo RS, Sutton JR, Wolfe EE, Reeves JT 1991 Increased dependance on blood glucose after acclimatization to 4,300. J Appl Physiol 70:919-927

26. Bursztein S, Elwyn DH, Askanazi J, Kinney JM 1989 Fuel utilization in normal, starving and pathologic states. In: Bursztein S, Elwyn DH, Askanazi J, Kinney JM (eds) Energy Metabolism, Indirect Calorimetry and Nutrition. Williams \& Wilkins, Baltimore, pp 119-171

27. Acheson KJ, Zahorska-Markiewicz B, Pittet P, Anantharaman K, Jéquier E 1980 Caffeine and coffee: their influence on metabolic rate and substrate utilization in normal weight and obese individuals. Am J Clin Nutr 33:989-997

28. Beavo JA, Rogers NL, Grofford OB 1970 Effects of xanthine derivatives on lipolysis and on adenosine $3^{\prime} 5^{\prime}$-monophosphate phosphodiesterase activity. Mol Pharmacol 6:597-604

29. LeBlanc J, Jobin M, Côté J, Samson P, Labrie A 1985 Enhanced metabolic response to caffeine in exercise-trained human subjects. J Appl Physiol 59:832-837

30. Bryan AC, Bowes G, Maloney JE 1986 Control of breathing in the fetus and the newborn. In: Fishman AP (ed) Handbook of Physiology, The Respiratory System, Sect. 3. American Physiologic Society, Bethesda, MD, pp 621-647 